\title{
The Role Leadership Style Plays in the Integration of Health Management Information System
}

\author{
Caroline Kawila \\ Kyalo \\ Department of Health \\ System Management \\ Kenya Methodist \\ University
}

\author{
G. W. Odhiambo- \\ Otieno \\ Department of Health \\ Sciences \\ Rongo University
}

\author{
George Otieno, PhD \\ Department of Health \\ Management and \\ Informatics \\ Kenyatta University
}

\author{
Wanja Mwaura- \\ Tenambergen, PhD \\ Department of Health \\ System Management \\ Kenya Methodist \\ University
}

\begin{abstract}
This study aimed to establish the role played by leadership style in the integration of health management information systems (IHMIS). An integrated HMIS is a software solution that spans the range of business processes that enables organizations to gain a holistic view of the business enterprise (Alvarez, 2007). An IHMIS supports the different levels of healthcare in terms of information exchange and flow, and the integration of business functions as diverse as patient care, accounting, finance, human resources, operations, sales, marketing, patient information and even the supply chain. Three approaches of leadership styles were tested to see how they influence integration of HMIS; i) Lassiez-faire ii) Transactional and iii) Transformational. A mixed method research design was used. A sample size of 288 respondents stratified in three levels of healthcare (tier 1,2, and 3) were purposively selected to participate in this study. The respondents included the in-charges, health records and information officers and sub-county and county health management teams members. A questionnaire and a key informant interview guide were used to collect primary data. The questionnaire was analyzed using SPSS and the Key Informant Interview using content analysis. The selection and appropriateness of leadership styles are significant factors for assuring organization success. Good execution of leadership transpires through the availability and access to information during decision making. The information system in an organization is dependent on the leadership behavior on decision making authority in groups. To a great extent Laissez-faire leadership style was found to dominate in the health sector in Kenya, with a few managers practicing Transactional Leadership Style. Laissez-faire leadership style was however found to have a negative and none significant effect in the integration of HMIS, $(\mathrm{r}=.121, \mathrm{P}=.060)$, this type of leadership plays the role of fragmenting the information systems. Transactional leadership style was moderately significant $\left(\mathrm{r}=478^{* *}, \mathrm{P}=.000\right)$, its role was in between fragmenting HMIS and Integrating them at the same time. Transformational leadership style was quite significant in the integration of HMIS $\left(\mathrm{r}=.765^{* *}, \mathrm{P}=.000\right)$, this type of leadership style portrayed a positive and significant role in integrating HMIS. The study therefore recommends that healthcare managers should embrace the leadership style that fully encourages team work, because this kind of a leadership style automatically leads to integration of HMIS.
\end{abstract}

\section{General Terms}

Health Management Information System, Health System Strengthening, Leadership Styles, Health Information System

\section{Keywords}

Integrated Health Management Information Systems (IHMIS), Laisse-Faire Leadership Style, Transactional Leadership Style, Transformational Leadership Style, Teamwork

\section{INTRODUCTION}

Studies by previous scholars have reported a positive impact of leadership style adopted on information systems success in organizations. For example a participatory leadership style can lead an organization to maximize productivity and achieve business goals. Given that modern organizations critically depend on information systems i.e. the different groups in an organization, the impact of leadership style has received little scrutiny in the health sector. The leadership role influence employees' behavior in several ways including guiding employees through the work process. Attention has been given to exploring factors that enhance information systems success however little attention has been given to leadership styles adopted in a health organization despite their potential of being effective (Humaidi \& Balakrishnan, 2015). Leadership style deserves more attention if integration of HMIS is to be successful. Health management information system (HMIS) is a collection of sub-systems which are interconnected with each other and work together in harmony to achieve one goal; processing data into information that can be useful to management in the decision -making processes (Alfian, 2016). Most researches in the Information System field have often focused on very specific managerial roles, such as allocating resources, monitoring outcomes, and controlling and coordinating people and work environments. While these managerial behaviors are undoubtedly important, they encompass only a small portion of a leader's role and thus primarily in obtaining efficient operations. However, the role of a leader also includes motivating employees and adapting to changing conditions (Alfian, 2016). This research categorizes integration of HMIS into two levels; first level involves integration of HMIS within a facility, second level of integration of HMIS across tiers in a health system. Each level whether at the facility or across the health system forms an information system that should be feeding into each other for improved care. This means working together as a team, which is also influenced by leadership style. Under such a perspective, health workers in each level of care are viewed as data or information controllers and processors for decision making. This understanding is quite relevant when evaluating the impact of leadership style on integration of HMIS. Laissez-faire gives employees authority to work as they choose, meaning employees work on their own so long as they achieve the set organizational goals. Transactional leadership style on the other hand, allows or deny subordinates a say in the leadership process. Transformational leadership style involves the dynamic interaction among 
people with varying roles that align themselves to solve specific goals. The transformational leadership style advocates for teamwork hence making integration of HMIS easy. The key functions of an IHMIS is to collect, store, disseminate and present data to health workers for decision making; their utility for decision makers is depended on whether they provide quality and timely information. This study recognizes though that there is no one leadership style that is effective in all information systems situations however believes that an appropriate leadership style is required if integration of HMIS was to be achieved (Humaidi \& Balakrishnan, 2015)

\section{LEADERSHIP STYLES ADOPTED IN HEALTHCARE ORGANISATIONS}

Laissez-Faire is concerned primarily with organizational performance. Laissez-faire leadership gives authority to employees to work as they choose with minimal or no interference. They do not give direct orders. Such a method involves delegation of decision-making and tasks by leaders to their subordinates. They keep abreast of what is occurring in the company and are available when advice and input is needed, but adopt a hands-off approach and let the employees work on their own as long as they achieve the set organizational goals. Fortunately, an information system takes the form of the organization. As previously described HMIS is a collection of sub-systems which are interconnected with each other and should work together to achieve one goal. However Laissez-faire leadership style allows workers to work independently without necessarily being concerned with what the other person is doing. Meaning health workers will not be required to operate as a team. This leadership style is likely not to favor the IHMIS because everyone works based on their own will, it does not encourage team work (Yahaya \& Ebrahim, 2016).

Transactional leadership style involves subordinates in the leadership process however, the leader retains the right to give or deny any subordinate a say in the leadership process (AbuNahleh, 2013). It is an open approach to leading, where decision making is shared and the views of a team or group are valued because they contribute to the vison, goals and decision that are made. Transactional leadership is also known as participative leadership, capturing the ideas of involvement and engagement. This kind of leadership encourages discussions and information sharing therefore builds commitment as individuals agree together what needs to be done. This builds a sense of belonging and demonstrates that skills and expertise are valued in an organization. This is an important aspect when it comes to integration of HMIS. Transactional leadership occurs when one person connects with others for the intention of an exchange of valued things such as information that can be economic or political or psychological in nature (Yahaya \& Ebrahim, 2016). Burns noted that both parties have related purposes, but the relationship does not go beyond the exchange of valued information that benefits the two parties. The relationship is not likely to trigger extra-role behavior of followers. It also does not bind leader and follower together in a mutual and continuing pursuit of a higher purpose (Burns, 1978). Bass proposed that transactional leadership is characterized by the transaction or exchange of information that takes place among leaders, colleagues, and followers. The exchange is based on the discussion between leaders and followers on the requirements and rewards that the followers will receive if they satisfy those conditions. Transactional leaders exchange things of value with followers to advance both parties' requirements (Ivey and Kline, 2010). Followers fulfill the leader's requirement in exchange for praise and rewards or the avoidance of punishment for nonperformance or lack of goal achievement. Thus, transactional leadership is realistic as it focusses on meeting the specific aims or goals (Aarons, 2006). Transactional leadership can be applied in many settings and is appropriate in encouraging employees to adhere to practice standards (Aarons, 2006).

Transformational leadership involves the process of dynamic interaction among people with varying roles who align themselves to solve specific goals. Transformational leadership occurs when one or more persons engage with others in such a way that leaders and followers raise one another to higher level of motivation and morality. Transformational leadership approach appeals to higher ideals and moral values and empower followers to produce profound and fundamental change (Yahaya \& Ebrahim, 2016). Transformational leadership style provides deeper levels of connection and higher levels of commitment, performance, and morality of both leader and follower. This style helps managers identify and develop shared values and empower others. It influences workers to produce not only quality work but more quantity of work, and use creativity in problem solving. Transformational leadership focusses on leaders transforming abilities. It is a process of changing and transforming an organization by increasing employees' motivation, building commitment, and empowering staff to achieve organizational goals. In other words this style is able to enhance the commitment of employees through shared values and shared vision. Transformational leadership focusses on the organization and direct commitment towards the organizational goals. It influences workers to focus on collective interest instead of self-interest (Yahaya \& Ebrahim, 2016). The communication is two-way and frequent between leaders and subordinates on defining problems and devising solutions.

\section{EMERGING TRENDS OF HMIS} 3.1 Community based health information systems

Community health workers have been trained to be able to collect relevant information within their villages (such as the number of births, cases of malaria, immunization coverage). This information should be entered in a central system to make the information available to the county health department to inform decision making. (Wanjala \& Odhiambo-Otieno, 2016). However findings in this study showed very minimal engagement if any between the community health workers and the county health department. The leadership style displayed here is laissez-faire. A Community based health Information System (CBHIS) is a type of health information system that is based on the rural community and informal settlements of urban areas. The development of comprehensive community based health information systems is increasingly becoming important for measuring and improving the quality of health services. Many developing countries including Kenya have made efforts to strengthen their national health information systems to provide information for decision-making in managing health care services (Jeremie, Kaseje, Olayo, \& Akinyi, 2014). However Community Units are working autonomously with little attention from the health system managers.

\subsection{Electronic Health Records}

There is increased use of Electronic Health Record (E.H.R) systems within individual practices and organizations. This 
has resulted to an elegant and systems based infrastructure that allows patient information to be available when and where it is needed, supports seamless coordinated services across an organization (medical and non-medical), and, provides ready access to comparative reporting and predictive modeling that supports the functioning of Health System activities from the local to the national level (Khalifa, 2013). A health record is created and maintained for the purposes of communication among care givers, protecting the legal interest of the patient, the physician and the facility, sustaining reimbursement claim, providing data for medical education and research and supporting quality healthcare improvement initiatives. E.H.R are electronically stored and can be shared across different health care settings, however most healthcare institutions do not share these records despite the fact that they can be useful to other players in the health sector. Findings in this study showed that E.H.R are mostly constrained and used within an institution hence adapting to transactional leadership style.

\subsection{District Health Information System 2}

District Health Information System (DHIS2); a free open source software that can be customized to integrate health information management activities. (DHIS2.org). DHIS2 helps governments and health organizations to manage their operations more effectively, monitor processes and improve communication. The DHIS2 is a tool for establishing a process that is used to continuously improve clinical and administrative operations ((Rahimi, Vimarlund, \& Timpka, 2009)). The DHIS2 is supposed to take care of actions at the strategic, tactical and operational level. Functions of the system at the different levels include: at the strategic level provision of information necessary to inform resources allocation and provides information to inform policy. At the tactical level the system helps managers at this level to ensure that work processes are followed. This is informed by optimal use of the HMIS at the operational level. The process informs administrative functions for instance establishing and implementing strategy and managing human resources, physical assets and information systems. At the operational level the system should support accomplishment of typical clinical functions such as medical services and patient support. The functioning of the system is quiet well outlined. However on the ground the reality is that the system is only functional at the strategic level. The tactical level and the operational level operate using silo systems, then extract information that they key in in DHIS2. There is no direct linkage between the three levels. This is evident also in the leadership style in the health system. There is lack of an open system leading to reporting what the health systems leaders perceive to be relevant and convenient.

\subsection{Integrated health management information system}

An IHMIS is meant to interlink all the available HMIS from the community to the health care organizations then to the county health management teams. It is a combination of all the systems CBHMIS, E.H.R and DHIS2 into one system. Therefore compatibility and operability of the systems is quiet important in enhancing integration of HMIS. The system will adapt transformation leadership style where every player in the sector is a team player. Information will be shared across the health sector. Hence, improving monitoring and control, resource allocation and policy formulation. The system will play a dynamic role of enhancing interactions among people within the system with different roles that are aligned to achieving better health outcomes. A Health Information
System (HIS) is a system that integrates data collection, processing, reporting, and use of the information necessary for improving health service effectiveness and efficiency through better management at all levels of health services (Teklegiorgis, Tadesse, Mirutse, \& Lerebo, 2016). The system is expected to fulfill the information needs of an individual, a group of individuals, the management functionaries. Information sharing and appropriate technological support are enablers of HMIS integration. Manager's involvement in monitoring and evaluating quality of service delivery is also required in integrated systems. Valid, useful indicators and standardized reporting allow for performance comparisons among individual, organizations and groups of healthcare providers. Since integration of HMIS favor's an interdisciplinary approach to management, team members must have clear roles, responsibilities, and accountabilities, and these should be supported by a policy and procedural framework. Healthcare teams should also know and agree on the care provider with overall responsibility for directing and coordinating service delivery. Managers should be aware of any organizational policies outlining the expectations at each level of care. Another potential area of concern for doctors in an integrated HMIS relates to the appropriate reporting. Hospitals should establish appropriate thresholds and pathways for reporting within the organization. An improved and harmonized health reporting system is critical for health system strengthening since it can generate timely information for proper planning, monitoring and evaluation of service delivery at all levels of the health system (Asangansi, 2012).

\subsection{Influence of leadership style on IHMIS}

A good HMIS streamlines reporting because it avoids parallel reporting systems and promotes single reporting (WHO \& ROWP, 2004). Within the health sector there are a myriad stakeholders who perform different functions with the aim of improving health outcomes, but there has to be a centralized data center for better decision making (Baarah et al., 2014). This implies that integration is highly dependent on the leadership style adopted. The theory of organization by (Gulick, 1937), informs the study on its structure of coordination. It also emphasizes that the only way to determine how activities are organized in an organization is through the reporting structure and division of work. Therefore the division of work is the foundation of an organization. Work according to (Gulick, 1937), is divided for two main reasons; nature, capacity, skills and specialization required for a certain job, however at the end of the day the goal to be achieved is one.

In Table 1, the different leadership styles were correlated with integration of HMIS and study findings showed that all were significantly correlated with integration of HMIS apart from Laissez-Faire leadership which was insignificant. Transformational Leadership had the strongest correlation with integration of HMIS. This implies that for integration to take place quickly the health system managers must adopt to transformational leadership style. The challenge was most healthcare institutions were practicing Laissez-faire leadership style. Unfortunately this leadership style does not encourage integration. 
Table 1. The relationship between leadership style adopted and IHMIS

\begin{tabular}{|l|l|l|}
\hline Leadership style & $\begin{array}{l}\text { Integration of } \\
\text { HMIS }\end{array}$ & P- Value \\
\hline Transactional & $.478^{* *}$ & 0.000 \\
\hline Laissez-Faire & .121 & 0.060 \\
\hline Transformational & $.765^{* *}$ & 0.000 \\
\hline
\end{tabular}

**. Correlation is significant at the 0.01 level (2-tailed).

The Leadership Style Adopted as indicated in Table 2, $F$ is 303.991, is significant at $p<.001$. This result tells us that there is less than a $0.1 \%$ chance that an $F$-ratio this large would happen if the null hypothesis were true. Therefore, we can conclude that our regression model result is significantly a good predictor of integration of HMIS. The regression model overall predicts integration significantly well.

Table 2. Leadership Style adopted and Integration of HMIS: Model Validity

\begin{tabular}{|l|l|l|l|l|l|}
\hline & $\begin{array}{l}\text { Sum of } \\
\text { squares }\end{array}$ & df & $\begin{array}{l}\text { Mean } \\
\text { Square }\end{array}$ & F & Sig \\
\hline $\begin{array}{l}\text { Regressio } \\
\mathrm{n}\end{array}$ & 69268.641 & 1 & $\begin{array}{l}69268.64 \\
1\end{array}$ & $\begin{array}{l}303.99 \\
1\end{array}$ & $\begin{array}{l}.00 \\
0\end{array}$ \\
\hline Residual & 54915.243 & $\begin{array}{l}24 \\
1\end{array}$ & 227.864 & & \\
\hline Total & $\begin{array}{l}124183.88 \\
5\end{array}$ & $\begin{array}{l}24 \\
2\end{array}$ & & & \\
\hline
\end{tabular}

a. Dependent Variable: Integration of HMIS

b. Predictors: (Constant), Leadership Style

Study findings in Table 3 prove that leadership style adopted accounts for $63.1 \%$ of the variation in IHMIS $\mathrm{R}^{2}=.631$. Table 3 , shows that $\beta 0$ is 51.702 , meaning that when the leadership style at a standstill (when $X=0$ ), the model predicts that 51.702 integration will still take place. However when the leadership styles adopted changes then integration will also change, as shown in Table 3 with 1.846. Therefore, if our predictor variable is increased by one unit (if the leadership style adopted is increased by 1 ), then our model predicts a 1.846 increase in integration.

Table 3. Leadership Style adopted and Integration of HMIS: Regression weights

\begin{tabular}{|l|l|l|l|l|l|l|}
\hline & $\begin{array}{l}\text { Unstandardi } \\
\text { zed } \\
\text { Coefficients } \\
\text { B } \\
\text { Std. Error }\end{array}$ & $\begin{array}{l}\text { Standardi } \\
\text { zed } \\
\text { Coefficien } \\
\text { ts } \\
\text { Beta }\end{array}$ & $\mathbf{R}^{2}$ & $\mathbf{T}$ & $\begin{array}{l}\text { Sig } \\
\cdot\end{array}$ \\
\hline Constant & $\begin{array}{l}51.70 \\
2\end{array}$ & $\begin{array}{l}7.11 \\
3\end{array}$ & & & $\begin{array}{l}7.26 \\
9\end{array}$ & $\begin{array}{l}.00 \\
0\end{array}$ \\
\hline $\begin{array}{l}\text { Leaders } \\
\text { hip style }\end{array}$ & 1.846 & .106 & .747 & 0.63 & $\begin{array}{l}17.4 \\
3\end{array}$ & .00 \\
0
\end{tabular}

a. Dependent Variable: Integration of HMIS

As shown in Table 4 below, in a multiple regression analysis Transactional and Transformational leadership style remain predictive and significant. However, Laissez-faire leadership style shows a negative effect on integration of HMIS.
Table 4. Combined effect of the specific leadership styles on Integration

\begin{tabular}{|c|c|c|c|c|c|}
\hline & $\begin{array}{l}\begin{array}{l}\text { Unsta } \\
\text { ed } \\
\text { Coeff }\end{array} \\
\text { B } \\
\text { Std. }\end{array}$ & $\begin{array}{l}\text { lardiz } \\
\text { ents } \\
\text { ror }\end{array}$ & $\begin{array}{l}\text { Standardiz } \\
\text { ed } \\
\text { Coefficient } \\
\text { S } \\
\text { Beta }\end{array}$ & $\mathbf{T}$ & $\begin{array}{l}\text { Sig } \\
\cdot\end{array}$ \\
\hline Constant & $\begin{array}{l}68.73 \\
5\end{array}$ & $\begin{array}{l}7.30 \\
8\end{array}$ & & 9.406 & $\begin{array}{l}.00 \\
0\end{array}$ \\
\hline Transactional & 1.089 & .215 & .216 & 5.066 & $\begin{array}{l}.00 \\
0\end{array}$ \\
\hline Laissez-faire & $\overline{1}-156$ & .587 & -.080 & $-\overline{1.970}$ & $\begin{array}{l}.05 \\
0\end{array}$ \\
\hline $\begin{array}{l}\text { Transformatio } \\
\text { nal }\end{array}$ & 2.699 & .168 & .702 & $\begin{array}{l}16.04 \\
4\end{array}$ & $\begin{array}{l}.00 \\
0\end{array}$ \\
\hline
\end{tabular}

a. Dependent Variable: Integration of HMIS

\section{DISCUSSION}

A leader in HMIS integration is someone who is responsible for owning up, steering and driving forward the implementation efforts towards achievements of the set organizational goals. This study found that among the three leadership styles, transformational leadership style has the highest influence and is positively correlated to the integration of HMIS. These findings are in consistent with a study by (Yahaya and Ebrahim, 2016) who found a positive correlation between transformational leadership styles and information System. The study findings conclude that leadership style adopted can play two roles in the formation of information systems for instance, it can either encourage fragmented information systems or integrated information systems. Laissez-faire encourages fragmented information systems, Transactional is in between fragmented and integrated information systems, while Transformational leadership style encourages integrated information systems.

\subsubsection{Laissez-faire}

After examining the three leadership styles it is evident that Laissez fair has a negative effect when it comes to integration of HMIS, this is because employees are let to work as they chose with minimal or no supervision so long as they do their jobs. This indicates that team work is not a virtue in this kind of set up, yet for integration to work well team work is key, bearing in mind that an information system takes the form of operation of an institution. A leader should be the architect who drives the organization in implementing new innovation by closely engaging the employees closely. Collaborative leadership is an important dynamic capability required to drive performance in organizations operating in a dynamic environment like the health sector.

From this finding it can be concluded that, it is possible that the reason why integration of HMIS has not been achieved in the health sector is because majority of the organizations are practicing Laissez faire leadership style. As long as the objectives of the organizations are met, the leaders are okay, however as indicated above this results to a negative effect when it comes to integration of HMIS.

\subsubsection{Transactional}

Transaction leadership style was found to have a positive and significant relationship with integration of HMIS because it encourages participative leadership. This style encourages discussions and information sharing, hence builds a sense of 
belonging and demonstrates staff skills and expertise are valued. This is an important aspect in integration of HMIS. This leadership style was however found not to be as effective as the transformational leadership style, this finding agrees with that of (Erhart and Nauman, 2004).

\subsubsection{Transformational}

Transformational leaders are expected to give directions and create an enabling environment for employees to drive the integration of HMIS. This Leaders foster, nourish and support new ideas, new products application. That is why the leadership style adopted has a great influence when new ideas and products are introduced in an organization. This is the leadership style is committed to executive change in tandem with committed members of a group. Burns theorized that transformational leaders cause change in individuals and organizational cultures while transactional leaders work in the existing culture. IHMIS brings in change hence transactional leadership would be best to adopt. An IHMIS is a collection of subsystems which are interconnected with each other and work in harmony to achieve one goal of process data into information needed by management in decision making process when carrying out its functions (Alfian, 2016). A quality HMIS means integration of the various levels in the health system. This study is in agreement with the study done by (Alfian, 2016) revealing that transformational leadership influence on the success of HMIS integration.

\section{ACKNOWLEDGMENTS}

Our thanks to the respondents (health workers), the Kiambu, Mombasa and Kitui county members' leadership who participated or gave authority to allow us to conduct this study in the various public facilities in their counties.

\section{REFERENCES}

[1] Alfian. (2016). How-Leadership-Style-Impacts-TheManagement-Information-System-Quality-a-TheoryticalStudy.pdf, 5(06).

[2] Humaidi, N., \& Balakrishnan, V. (2015). Leadership Styles and Information Security Compliance Behavior: The Mediator Effect of Information Security Awareness.

[3] Abu-Nahleh, I. I. (2013). The Role of Leadership Theories in Information Technology Acceptance: Case Study at Al-Hikma Pharmaceutical Company.
[4] Yahaya, R., \& Ebrahim, F. (2016). Leadership styles and organizational commitment: literature review. Journal of Management Development, 35(2), 190-216.

[5] Ivey GW and Kline TJB (2010). Leadership and Organizational Development.

[6] Pepela, W., \& Odhiambo-Otieno, G. (2016). Community health information system utility: A case of Bungoma C ounty Kenya..

[7] Jeremie, N., Kaseje, D., Olayo, R., \& Akinyi, C. (2014a). Utilization of Community-based Health Information Systems in Decision Making and Health Action in Nyalenda, Kisumu County, Kenya.

[8] Khalifa, M. (2013). Barriers to Health Information Systems and Electronic Medical Records Implementation. A Field Study of Saudi Arabian Hospitals.

[9] DHIS. (n.d). Data management and analytics.

[10] Rahimi, B., Vimarlund, V., \& Timpka, T. (2009). Health information system implementation: A qualitative metaanalysis. Journal of Medical Systems, 33(33), 359-368

[11] Teklegiorgis, K., Tadesse, K., Mirutse, G., \& Lerebo, W. (2016). Level of data quality from Health Management Information Systems in a resources limited setting and its associated factors, eastern Ethiopia. SA Journal of Information Management, 17

[12] Asangansi, I. (2012). Understanding HMIS Implementation in a Developing Country Ministry of Health Context - an Institutional Logics Perspective.

[13] WHO, W. H. O., \& ROWP, R. O. for the W. P. (2004). Developing health management information systems: a practical guide for developing countries.

[14] Baarah, A., Kuziemsky, C. E., Chamney, A., Bindra, J., \& Peyton, L. (2014). A design strategy for health information systems to address care process management.

[15] Gulick, L. (1937). Papers on the science of administration: Notes on the theory of organization. 